\title{
Web based remote water tanker reachability, monitoring \& controlling system in drought areas
}

\author{
${\text { Dharmadhikari Ashvini }{ }^{1,} \text { Jadhav Maheshwari }^{2,} \text { Shinde Savita }}^{3}$ Sonje Priyanka ${ }^{4}$ \\ ${ }_{1,2,3,4}$ (Computer engineering, SVIT College, Pune university, India)
}

\begin{abstract}
India is the country where the drought problem in villages is a major issue. Every year people have to suffer from the problem of water scarcity, although government allocate water tanker to each village but it is not guaranteed that it will reach to that particular village on time. So we focus on the water supply in drought areas in India. Our project is based on water tanker reach ability, monitoring and controlling system in which the numbers of tankers provided to the particular village are checked by detecting the signals from tankers to the well over some specific distance. It also checks the water level in well by using sensors. Each village is having a server which is able to keep records of all the water tankers with date and time and water level in well. These records are accessed by an administrator in the home ministry which is connected to each other through network.

The most important advantage in this application is to avoid the problem of water scarcity. Advanced RF communication is used for signals. RF is used because RF is capable of penetrating almost from every object. It is least affected by environment factors. Many types of wireless devices make use of RF fields. Thus this application can be one of the greatest boons in order to avoid drought problem. This advanced idea if implemented in India will definitely add to the technological development of our country. Finally, we conclude that embedded system is an emerging field and there is a huge scope for research and development.
\end{abstract}

Keywords: IIS: Internet Information System, LPT: Line Print Terminal, TTL: Transistor-Transistor Logic, RF: Radio Frequency, WAN: Wide Area Network

\section{INTRODUCTION}

Our project is based on embedded technology and its title is as follows "Web based water tanker reach ability monitoring and controlling system in drought areas in Indian villages".

In India there is a major problem of drought in every region. Many regions in India have to face the problem of water scarcity every year. So the areas coming under drought prone regions are increasing. To avoid this problem we are developing an application which will help out people to overcome from this severe condition.

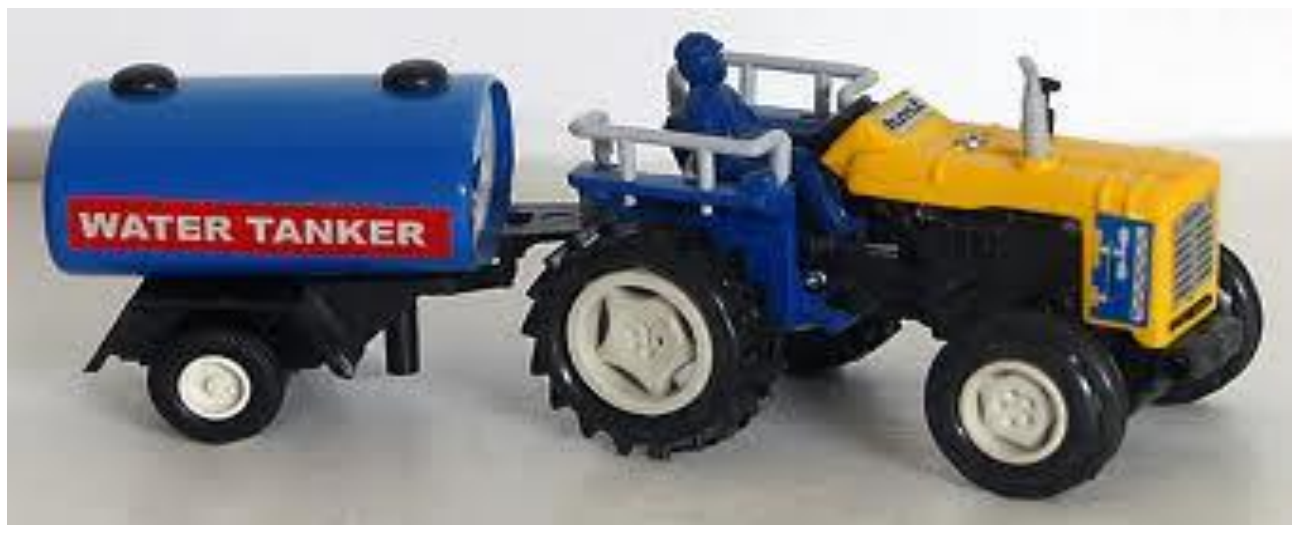

Government passes the tender of water tanker reachability to the particular or the group of villages that have the problem of water scarcity. But many times this pass tender result in fail condition due to improper management. Government passes the required tender but it happens that many times the allocated tanker does not reach to the particular village or drought affected area. So the problem remains as it is. The allocated tanker many times reaches to the area after a long time and does not provide the service up to the mark of water reach ability. Thus, there is a need to bring about some changes in the current technology which manages water distribution system. 
In this application with the help of RF transmitter and receiver the record of particular tanker is maintained. Whenever government passes the tender to allocated water tanker to particular village then the respective tanker had to reach the place within time. Its attendance is made with its Id no, day, date and time. Tanker will have to fill water in well because water level sensors will be present to check water level every time. The whole process has a control within the Home ministry department and the records are maintain properly thus solving the problem. This project highlights the advanced technological idea which will help in bringing some improvisation. This advanced idea if implemented in India will definitely add to the technological development of our country.

\section{LITERATURE SURVEY}

The drought condition regarding water management is observed in many parts of the world. So number of research and surveys are made about water resource management.

Mr. Ram Prasad Kafle has been attracted to natural resources management since his first master degree on Rural Development at Tribhuvan University in Nepal. Therefore, I decided to perform further research on the topic of rural drinking water in the Nepali hills for that master thesis. However, before this, I built up technical expertise regarding micro-hydro power in Nepal. Furthermore, during my working relationship with the Rural Village Water Resources Management Project (RVWRMP), functioning as a monitoring and evaluation officer, I was intrigued with water resource management and local level conflicts, arising while sharing water for drinking, irrigation and hydropower. During my research work, I have found very few studies carried out on local conflict caused by rural-urban water transfer. It may also be because the institutionalization of the water sector has been left untouched in Nepal since a long time.

The Indonesian Water Partnership also aims to establish synergy and cooperation for realizing the benefits of sustaining water for human welfare through the "Integrated Water Resources Management" approach. In pursuing its objectives, the Indonesian Water Partnership (KAI) has set up the following programs:

- To open web-site as a mean for disseminating information on water resources such that everybody has an access;

- To receive and disseminate information on water resources at the national, regional or international levels, as well as with other Country's Water Partnerships;

- To be part of the regional as well as global networking institutions for promoting Integrated Water Resources Management.

The Water Distribution System for the Village Punta Sirain, Panama. Ba Noire Designs has designed a water distribution system that will provide the 250-resident community of Punta Sirain, Panama with drinking water. The current water supply system is insufficient in that it provides water directly to only ten of about forty households. Spring water is collected in the toma-a 6,000 gallon $(22,700 \mathrm{~L})$, uncovered, water catchment and storage tank-and then gravity fed to the community. Since the toma is uncovered, the stored water is contaminated by debris and algae. Consequently, many of the children suffer from water borne illnesses.

The new design proposes that the toma be modified into a smaller three-chamber, covered spring box. This will help protect the spring water from contamination. The water will be pumped using solar power to a storage tank located on a hill fifty feet higher in elevation than the toma. The distribution system will gravity feed water from the storage tank to each of the forty homes in the community.

The current scenario in India related to the water tanker reachability in drought prone areas is not done in proper fashion. Due to this the people who are been affecting from such severe condition has to face many problems regarding water.

The drought situation in Maharashtra has continued to deteriorate in 2004. Deficient rainfall in Western Maharashtra and Marathwada regions for the last four years in succession has severely affected agriculture in the region, which is the main source of livelihood and employment. Following the failure of monsoon in 2003, the Government of Maharashtra declared drought in 11 districts of the State on October 15, 2003. These districts are: Pune, Satara, Sangali, and Sholapur (Pune Division), Nasik and Ahmednagar (Nasik Division) and Beed, Latur, Osmanabad and Aurangabad (Aurangabad Division). Altogether 71 talukas in these 11 districts are seriously affected by the drought, as shown in the table below: 
Table 1: List of Drought-affected Districts and Talukas

\begin{tabular}{|c|c|c|l|}
\hline Sr.No. & District & $\begin{array}{r}\text { No. of } \\
\text { affected } \\
\text { Talukas }\end{array}$ & \multicolumn{1}{|c|}{ Names of Talukas } \\
\hline 1 & Sholapur & 11 (All) & $\begin{array}{l}\text { Barshi, Karmala, Madha, Malshiras, } \\
\text { Mangalvedha, Mohol, Pandharpur, Uttar } \\
\text { Solapur, Sangola, Dakshin Solapur, Akkalkot. }\end{array}$ \\
\hline 2 & Sangli & 7 & $\begin{array}{l}\text { Jat, Kavatemahankal, Tasgaon, Miraj, Khanapur, } \\
\text { Atpadi, Kadegaon. }\end{array}$ \\
\hline 3 & Pune & 5 & Baramati, Daund, Indapur, Purandar, Shirur. \\
\hline 4 & Satara & 5 & Maan, Khatav, Khandala, Phaltan, Koregaon \\
\hline 5 & Ahmednagar & 14 All) & $\begin{array}{l}\text { Sangamner, Kopargaon, Shrirampur, Akola, } \\
\text { Pathardi, Parner, Shrigonda, Ahmednagar, } \\
\text { Rahata, Jamkhed, Shevgaon, Rahuri, Nevasa, } \\
\text { Karjat. }\end{array}$ \\
\hline 6 & Nashik & 6 & $\begin{array}{l}\text { Yevala, Sinner, Nandgaon, Chandvad, Devla, } \\
\text { Malegaon, }\end{array}$ \\
\hline 7 & Beed & 7 & Parli, kaij, Ashti, Patoda, Beed, Shirur, Wadvani. \\
\hline 8 & Osmanabad & 8 All) & $\begin{array}{l}\text { Osmanabad, Tuljapur, Umarga, Lohara, Kalamb, } \\
\text { Vashi, Bhum, Paranda }\end{array}$ \\
\hline 9 & Aurangabad & 2 & Vaijapur, Gangapur \\
\hline 10 & Latur & 4 & Latur, Renapur, Ausa, Nilanga. \\
\hline 11 & Jalna & 2 & Ambad, Ghansavangi. \\
\hline
\end{tabular}

Table 2.1 List of Drought-affected Districts and Talukas

The figure in the graph bar shows that the available, demand and utilizable water supply ratio in India. As per increasing population, the demand and utilization of water increases to great extent, but availability of water is decreasing day by day.

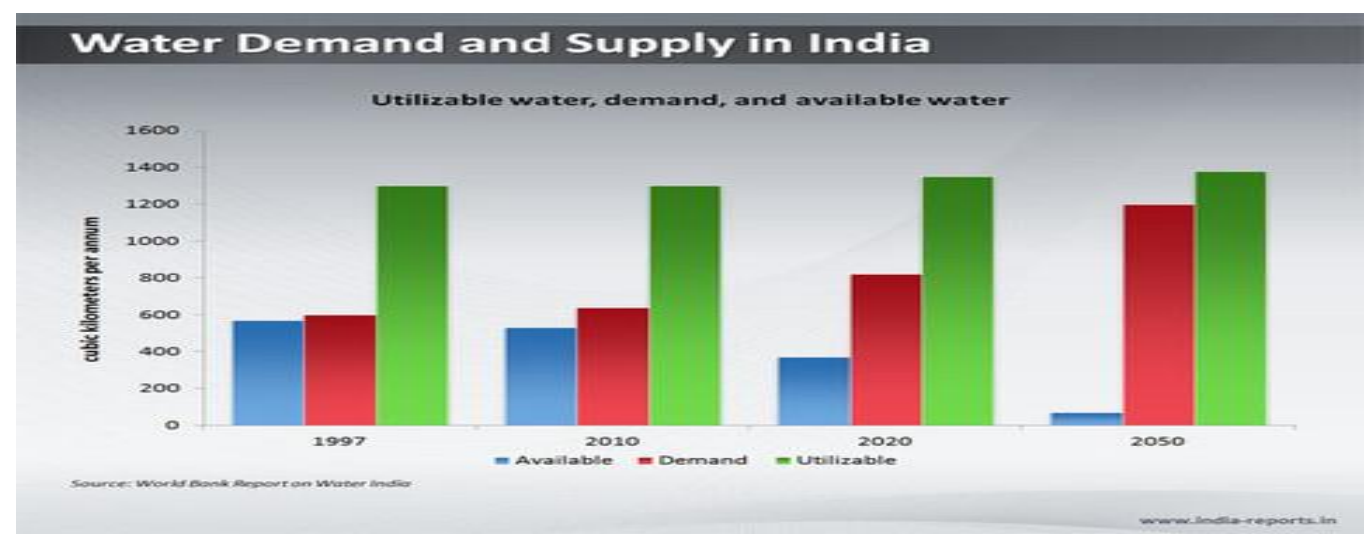

Figure 2.1 Water demand and supply in India

\subsection{Introduction}

\section{SOFTWARE REQUIREMENTS SPECIFICATIONS}

The theme of proposed system is to avoid corruption which is done in India about the drought prone areas.

\subsection{Project scope}

$>$ Avoids water scarcity problem.

D Suitable for long range applications.

DF signals can travel even if there is any obstacle between transmitter and receiver.

$>\mathrm{RF}$ transmission is more strong and reliable.

$>$ Easy maintenance of the system is possible.

$>$ Data is secure.

$>$ Less time consuming.

$>$ Easy to handle the system.

$>$ Data modification can be done easily.

\subsection{User classes and Characteristics}

There will be only one user class administrator. They will be categorized on the basis of their domain knowledge level, frequency of use, system privilege assigned to them. 


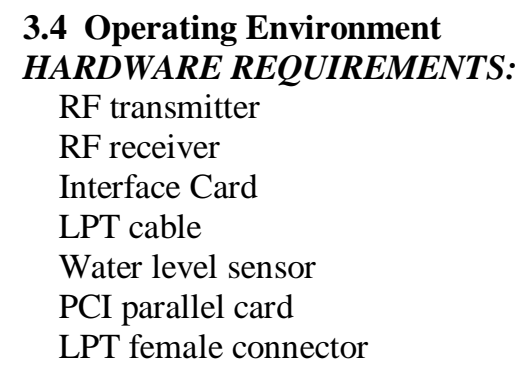

\section{SOFTWARE REQUIREMENTS:}

Front End: Asp.net, VB.net

Back End: SQL

O.S. Windows XP and above

MS visual studio 2005/08

IIS 5.6 and above

.NET framework 2.0, 2.5, 3.5

\subsection{Design and Implementation constraints}

\section{MATHEMATICAL CALCULATIONS}

1. Relationship between units of radio waves.

There are following 3 units of radio waves:

1. Hertz (Hz)

2. Kilohertz(KHz)

3. Megahertz(MHz)

The relationship between these units is like: $1,000,000$ Hertz=1000 kilohertz=1Megahertz

Radio waves are transmitted as a series of cycles, one after the other. The Hertz is equal to one cycle per second.

\section{Frequency emitted by particular tanker having RF transmitter.}

$\mathrm{F}=1 / 2 * \mathrm{PI}$ *adian LC

Where $\mathrm{F}=$ Frequency emitted by particular train

$\mathrm{L}=$ inductor

$\mathrm{C}=$ capacitor

\section{Explanation}

There are $2 *$ pi radians in a full circle. For the trigonometry to work out, the natural unit to measure the angles is the radian. It is possible to convert the radians to degrees(PI radians=180 degrees), but then factors of PI and 180 will appear in trigonometric formulas that operate in degrees.

\section{Relationship:}

1. $1 \mathrm{~Hz}=1 \mathrm{cycle} / \mathrm{sec}$

2. $1 \mathrm{MHz}=10^{\wedge} 6 \mathrm{~Hz}$

\section{Wavelength of $R F$.} formula:

The relationship between a radio signal's frequency and its wavelength can be found by following

Wavelength $=300 /$ frequency in $\mathrm{MHz}$

Even though radio waves are invisible, there is a measurable distance between the cycles of electromagnetic fields making up a radio wave. The distance between the packs of two consecutive cycles is measured in meters. Unit of wavelength=meters $(\mathrm{m})$.

\section{Formula to calculate power of RF signals.}

- $\mathrm{dBm}-\mathrm{The} \mathrm{Db}$ value is compared to $1 \mathrm{Mw}$.

- $\mathrm{dBw}$-The $\mathrm{Db}$ value is compared to $1 \mathrm{~W}$.

The power in dBs calculated from his formula: Power (in $\mathrm{Db})=10 * \log 10$ (Signal/Reference)

This list defines the terms in the formula: $1 . \log 10$ is algorithm base 10 .

Signal is the power of the signal(for example,50Mw). References is the references power(for example, $1 \mathrm{Mw}$ ). 


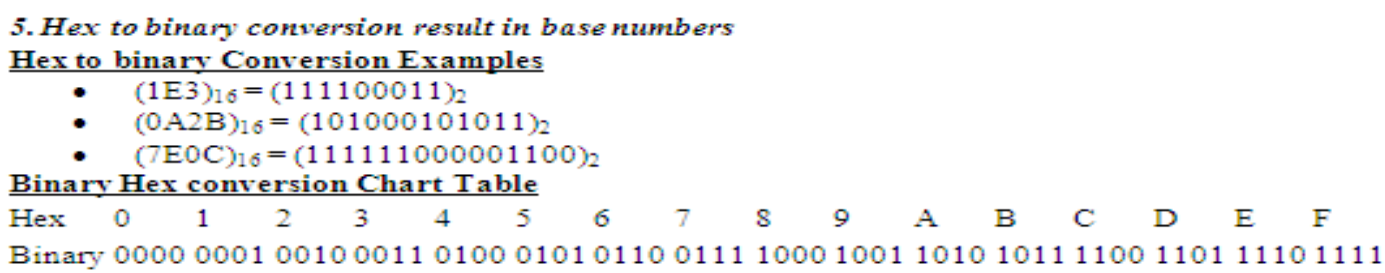

\subsection{Assumptions and Dependencies}

1. Tanker will definitely reach properly at the epic center.

2. Radio frequencies of transmitter and receiver.

3. Server is the another dependency.

\subsection{External Interface Requirements}

\section{$>$ User Interface}

User interface is required to

\section{$>$ Hardware Interface}

\section{- Transmitter}

The radio frequency transmitter is one element of a radio system. A radio transmitter design must consider multiple technical and regulatory factors. Typically a transmitter design includes the frequency of operation, generation of a carrier signal, optionally one or more frequency multiplication stages, a modulator, a power amplifier, and a filter and matching network to connect to an antenna.

\section{- Receiver}

A radio frequency receiver ( $\mathrm{RF}$ receiver) is a radio receiver that is usually composed of several radio frequency amplifiers followed by circuits to detect and amplify the audio signal. It is able to receive the signal transmitted by transmitter.

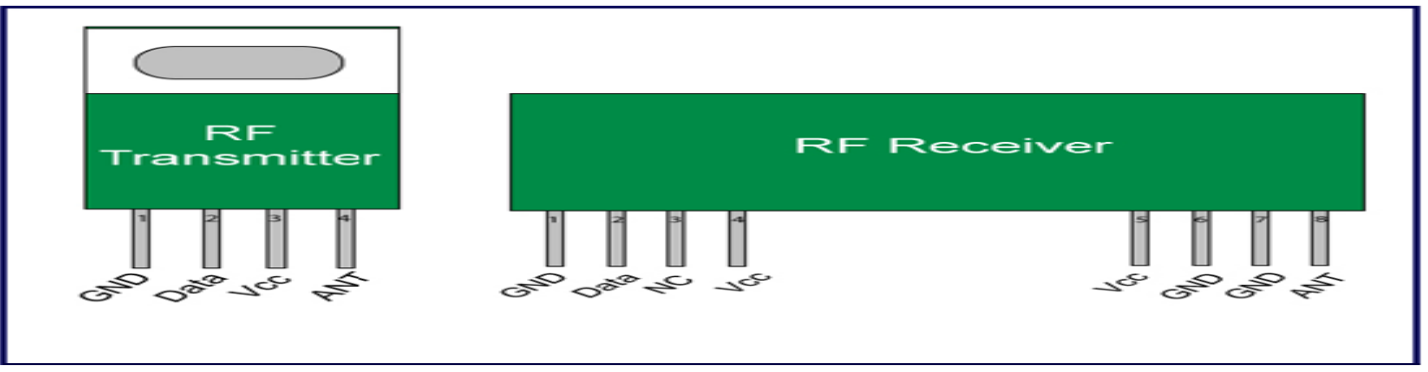

Figure 3.1 Pin diagram for RF Transmitter and Receiver RF Transmitter

Table 3.1 Pin description for RF Transmitter RF Receiver

\begin{tabular}{|c|l|l|}
\hline Pin No & Function & Name \\
\hline 1 & Ground (0V) & Ground \\
\hline 2 & Serial data input pin & Data \\
\hline 3 & Supply voltage; 5V & Vcc \\
\hline 4 & Antenna output pin & ANT \\
\hline
\end{tabular}

Table 3.2 Pin description for RF Receiver

\begin{tabular}{|c|l|l|}
\hline Pin No & Function & Name \\
\hline 1 & Ground (0V) & Ground \\
\hline 2 & Serial data output pin & Data \\
\hline 3 & Linear output pin; not connected & NC \\
\hline 4 & Supply voltage; 5V & Ycc. \\
\hline 5 & Supply voltage; 5V & Ycc. \\
\hline 6 & Ground (OV) & Ground \\
\hline 7 & Ground (OV) & Ground \\
\hline 8 & Antenna input pin & ANT \\
\hline
\end{tabular}


- TTL logic

Transistor-transistor logic (TTL) is a class of digital circuits built from bipolar junction transistors (BJT) and resistors. It is called transistor-transistor logic because both the logic gating function (e.g., AND) and the amplifying function are performed by transistors. TTL is notable for being a widespread integrated circuit (IC) family used in many applications such as computers, industrial controls, test equipment and instrumentation, consumer electronics, synthesizers, etc.

\section{- Water Level Sensor}

The water level sensor is conducive for liquids that have conductivity. The level probe and the evaluation unit can be connected using a long cable. The AC is provided on the probe for preventing electrode deterioration. There will be a +VCC supply in the water for working the circuit properly as water is good conductor of electricity.

\section{- LPT Cable}

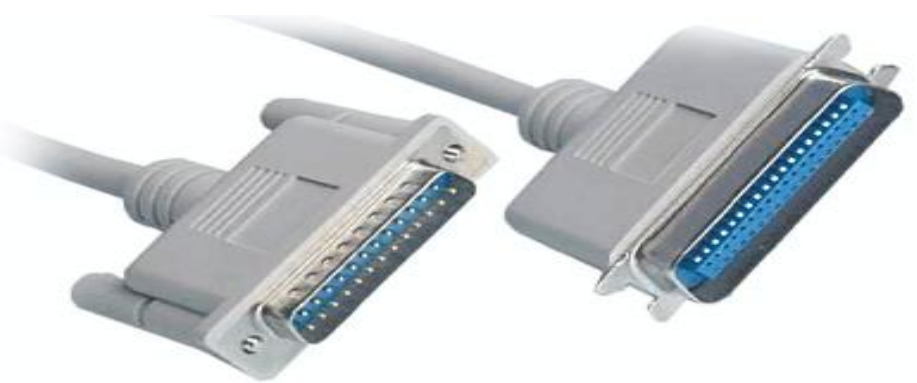

Fig: LPT cable

LPT cable is 25 pin cable \&it is specially used for printer interface purpose. We have modified it according to the requirement of our application. We used this cable for connecting hardware module to the CPU. One port of LPT cable which is shown in figure is replaced by Non-L-type male connector.

\section{- L-type female connector}

L-type female connector is attached to the hardware module which in turn is connected to the LPT cable.

\section{$>$ Software Interface}

\section{- IIS SERVER}

IIS, or internet Information Server, is the web server component of Microsoft Windows Server. It was introduced via the Windows NT Option Pack 1 for Windows NT 4.0.It has been included with all versions of Windows Server since the release of Windows 2000 Server, including Windows 2003 Server.

\section{FEATURES:-}

IIS is the default web server which is included with all versions of windows server. Since in this proposed system web pages are designed which are displayed after storing them on web server. This is supported by IIS server. In addition, IIS Server supports .Net technology which is used as software requirement in the proposed system.

\section{- APPLICATION SERVER}

An application server is a server that provides software applications with services such as security, data services, transaction support, load balancing, and management of large distributed systems. The term is often used for web servers that support the Java Platform, Enterprise Edition, however its use isn't restricted to Java.

\section{$>$ Communication Interface}

The Communication interface is going to be in Wireless mode.

\section{- Radio Frequency}

Radio frequency (RF) is the rate of oscillation in the range of about $3 \mathrm{KHz}$ to $300 \mathrm{GHz}$, which corresponds to the frequency of radio waves, and the alternating currents which carry radio signals. RF usually refers to electrical rather than mechanical osillations, although mechanical RF systems do exist. 


\subsection{NON-FUNCTIONAL REQUIREMENTS}

\section{$>$ Performance Requirement}

1. The system should be easy to handle to authenticated user.

2. Systems should give expected performance results.

3. The response time should be small.

\section{$>$ Security Requirement}

1. This application is used for particular gram.

2. Authenticated user has right to work on machine.

\subsection{OTHER REQUIREMENTS}

Legal requirements: License copy is essential.

\subsection{System Architecture}

\section{SYSTEM DESIGN}

$\mathrm{RF}$ transmitter is attached to the tanker and RF receiver is located at the well. The tanker continuously going to emit RF signal. When the tanker crosses the distance of the $2 \mathrm{KM}$ radius, the transmitted RF signal will be sensed by RF receiver situated near the well. A special type of transmitter IC is used at transmitter. The tanker is going to continuously transmit RF signal in the form of ASK (Amplitude Shift Keying).

The RF receiver located at well is connected to IC (Interface Card) which in turn is connected in parallel to microprocessor through LPT port.

The Interface card consists of two modules:

1. RF Decoder: - The received encoded information is sent to IIS server which consists of web pages for further processing through LPT port.

2. TTL Logic: TTL is the Transistor Transistor Logic. Which is the class of digital circuit built from bipolar junction transistor(BJT)and resistors

The schedule of the tanker is stored in database. Depending upon the particular transmitted frequency of the RF transmitter attached to the tanker sensed by the RF receiver situated near the well. When the tanker comes within the range at the receiver then PC will monitor the tanker. It also checks the water level in well by using sensors. Each village is having a server which is able to keep records of all the water tankers with date and time and water level in well. These records are accessed by an administrator in the home ministry which are connected to each other through network. We are going to design web pages which will electro dynamically control the switching. IIS 5.6 is used for designing the web pages.

In this proposed system radio frequency $(\mathrm{RF})$ is used because $\mathrm{RF}$ is capable of penetrating almost from every object. It is least affected by environment factors. In this RF system, the digital data is represented as variations in the amplitude of carrier wave. This kind of modulation is known as Amplitude Shift Keying (ASK). Radio frequency (RF) radiation is a subset of electromagnetic radiation with a wavelength of $100 \mathrm{Km}$ to $1 \mathrm{~mm}$, which is a frequency of $300 \mathrm{~Hz}$ to $3000 \mathrm{GHz}$ respectively. This range of electromagnetic radiation constitutes the radio spectrum and corresponds to the frequency of alternating current electrical signals used to produce and detect radio waves.

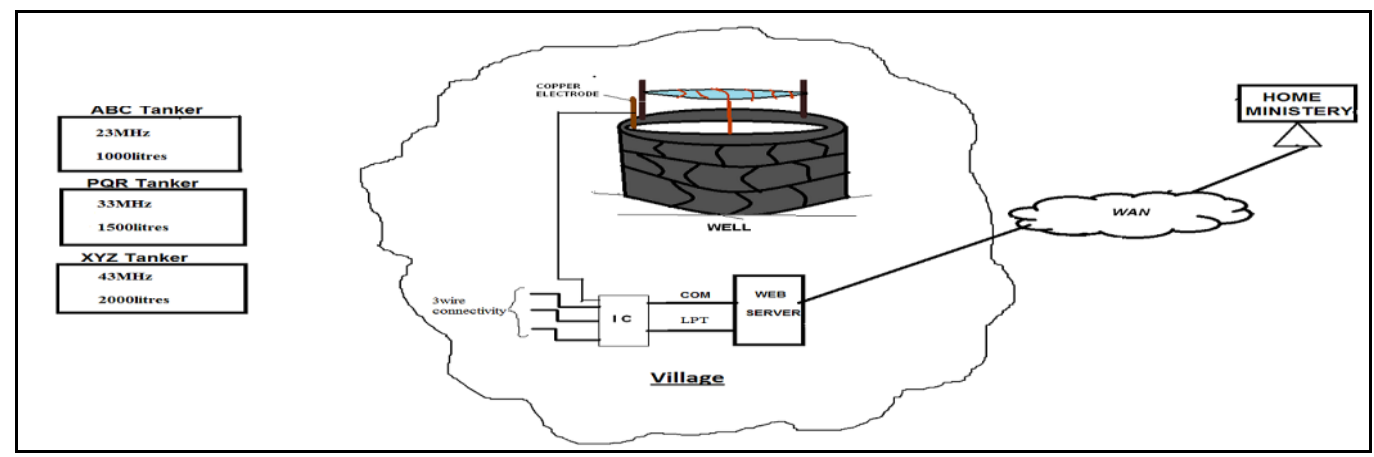

Fig 4.1 Block Diagram

In this we used the advanced RF communication is used for signals. The whole system is divided into three modules, the transmitter module and the receiver module and transistor circuitry. But the important thing to be noted here is that there is no connection between the transmitter and receiver section. Radio frequency (RF signal) makes this task very simple. 


\subsection{System Features}

1. We can control the whole operating system using web pages.

2. The system will Elecro-Dinamically control the water tankers.

3. The proposed system will provide the centralized control and it will maintain up-to-date records about each of the tanker.

4. The whole system will have control of home ministry to check the updations of each village in India.

\subsection{Hardware module}

\section{MODULES}

The hardware is divided mainly into two modules:

1. Interface module

2. Well module

\subsubsection{Interface module}

Interface module is specially designed for the purpose to check whether the particular tanker is reaching to particular destination or not. Overall function of Interface module is done by LPT port. It consists of L-type and Non L-type female connector.

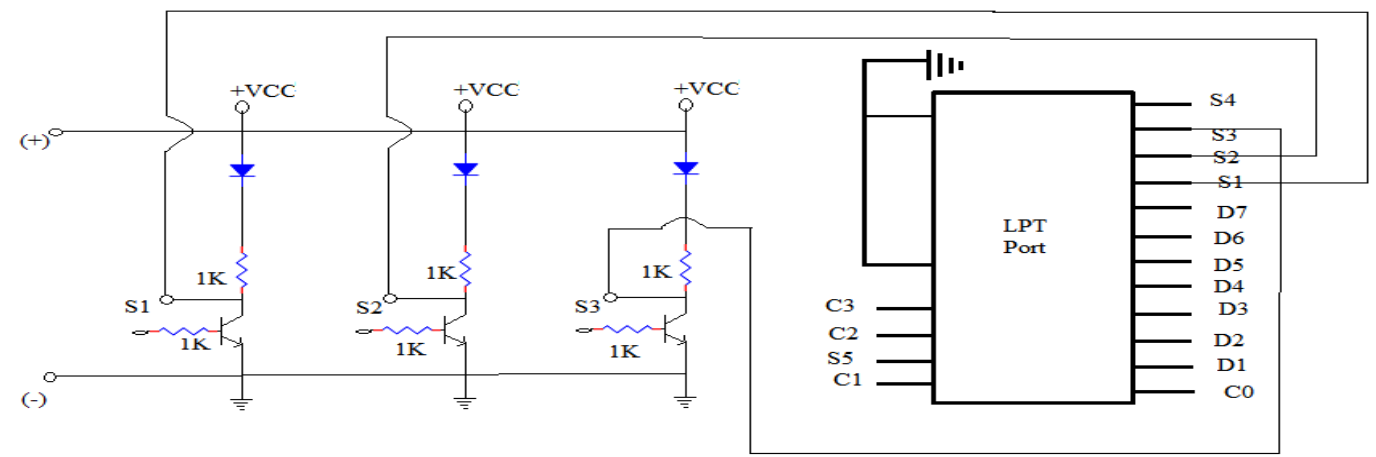

Fig 5.1 Circuit Diagram for Interface module

\subsubsection{Well module}

Well module is specially designed to check the water level in the well. Whenever the particular tanker inserts the water in the well, the water level get increases. That increased water level is checked with the help of sensors which is placed inside the well. +Vcc supply is given in the water as water is good conductor of electricity.

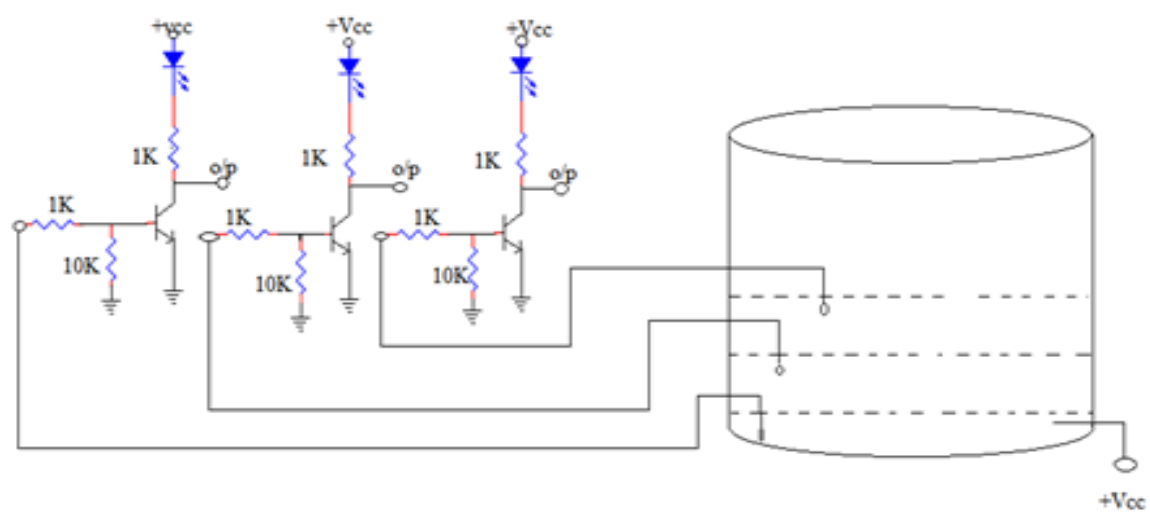

Figure 5.2 Circuit Diagram for well module

4.2 Software module

5.2.1 Windows module 


\section{- USER LOGIN PAGE}

Only authenticated user can login to the system by entering specific user name and password. This windows module is specially designed to indicate the server which is assigned to each village.

\subsubsection{Web module}

- LOGIN PAGE

It is used for authentication at the home ministry.

- HISTOGRAM PAGE

It is designed to represent pictorial view of the well before and after inserting water in the well.

- LOCATION SELECTION PAGE

It gives the list of gram from which authorized user can select a particular gram and are able to see all information regarding to respective gram.

\section{- TANKER MAINTENANCE PAGE}

It is used for storing the information about tanker

1. Tanker_id

2. Tanker date

3. Tanker attendence

4. Arrival and departure time of particular tanker

- Well MainTenanCE Page

It is used for storing well water level information about a particular village.

\section{TECHNICAL SPECIFICATION}

\subsection{Advantages}

- Reducing drought prone areas

-The most important application of the system is to reduce drought prone areas by providing sufficient number of water tankers to each village where there is need of water.

-Water supply must be guaranteed.

- Home ministry have control

-This sytem is having centralized control of home ministry.

-Home ministry can access records of any village where government has passed the tender of water tanker allocation.

- Suitable for long range applications

Signal through RF can travel through larger distances making it suitable for long range application.

- RF signals can travel without any obstacle.

RF signals can travel even when there is an obstruction between Transmitter and Receiver, it does not require any line of sight.

- RF transmission is more strong and reliable.

\subsection{Disadvantages-}

-System is prone to technical fault.

-Initial cost is high when gram office and well distance is more.

\section{REFERENCES}

[1]. The $6^{\text {th }}$ Edition of "Water distribution system operations and maintenance".

[2]. "Water Resources Management Towards Enhancement of Effective Water Governance in Indonesia". 24 February 2003.

[3]. "Water Distribution System for the Village Punta Sirain, Panama". December 11, 2009.

[4]. "Second Memorandum to the Government of India on Drought relief and mitigation in Maharashtra". 2004

[5]. "Water tanker distribution management system".

[6]. From the Journal Ice/Science(Virtual library) "Water Distribution System" by John Banyard, January 2011.

[7]. Journal of water resource planning and management. 